\title{
Auralcephalosyndactyly: a new craniosynostosis syndrome or a variant of the Saethre-Chotzen syndrome?
}

\author{
E LEGIUS, J P FRYNS, AND H VAN DEN BERGHE \\ Centre for Human Genetics, University of Leuven, Belgium.
}

SUMMARY A mother and son are reported with bilateral, symmetrical syndactyly of the third, fourth, and fifth toes, mild craniosynostosis of the coronary sutures, and small pinnae. The same combination of malformations was recently described as a new syndrome by Kurczynsky and Casperson in a mother and her daughter. ${ }^{1}$ In addition, in the present family, the mother had fusion of two cervical vertebrae and a partial duplication of the first metatarsal. The child had a bilateral cleft lip and palate. The question is raised whether these patients represent a new syndrome or a variant of the Saethre-Chotzen syndrome.

Saethre ${ }^{2}$ and Chotzen ${ }^{3}$ each independently reported the association of mild acrocephaly and asymmetry of the skull associated with partial soft tissue syndactyly of the second and third fingers and the third and fourth toes. Several other reports have confirmed autosomal dominant inheritance and variable expression of this syndrome (for review see Temtamy and McKusick ${ }^{4}$ ).

\section{Case report}

The proband, a male, was the first child of unrelated parents. At birth a bilateral cleft lip and palate was noted, together with cutaneous syndactyly of the fourth and fifth toes (complete on the left side and partial on the right side). No problems were noted in the perinatal period. At the age of eight weeks he was referred with his parents for further diagnosis and genetic counselling. Length was $57.5 \mathrm{~cm}$ (50th centile), weight $4.4 \mathrm{~kg}$ (25th centile), and head circumference $38 \mathrm{~cm}$ (25th centile), all within normal limits, and psychomotor development was adequate for age. There was a bilateral total cleft palate; the cleft lip had already been repaired. He was brachycephalic with slight exophthalmos and upward slanting palpebral fissures (fig 1). Bilateral

Received for publication 23 November 1988. preauricular pits and small ears were present. Examination of the chest, abdomen, and genitalia was normal. The fingers were relatively short and the feet showed the bilateral, symmetrical, cutaneous syndactyly already described and large toes (fig 2 ). Skull radiography showed a small anterior fossa and almost complete closure of the coronal sutures. Radiography of the extremities showed an abnormal, small, and curved fourth metatarsal and lack of ossification of the distal phalanges. Follow up at the age of four months showed normal psychomotor development and no evolution in the synostosis.

The mother had the same brachycephalic head shape with exophthalmos and ptosis (fig 3 ). She had small ears with incomplete development of the scaphoid fossa and small lobules. The uvula was short, but there was no cleft. Further clinical examination showed a short neck, short fingers, broad halluces, and asymmetrical, complete, cutaneous syndactyly of the toes (fourth and fifth toe on the left side and third, fourth, and fifth toes on

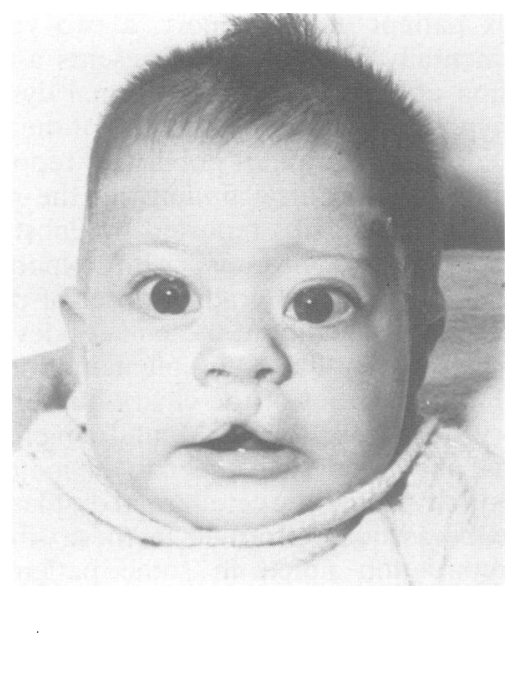

FIG 1 Proband at the age of four months, showing repaired lip, exophthalmia, and upward slanting palpebral fissures. 


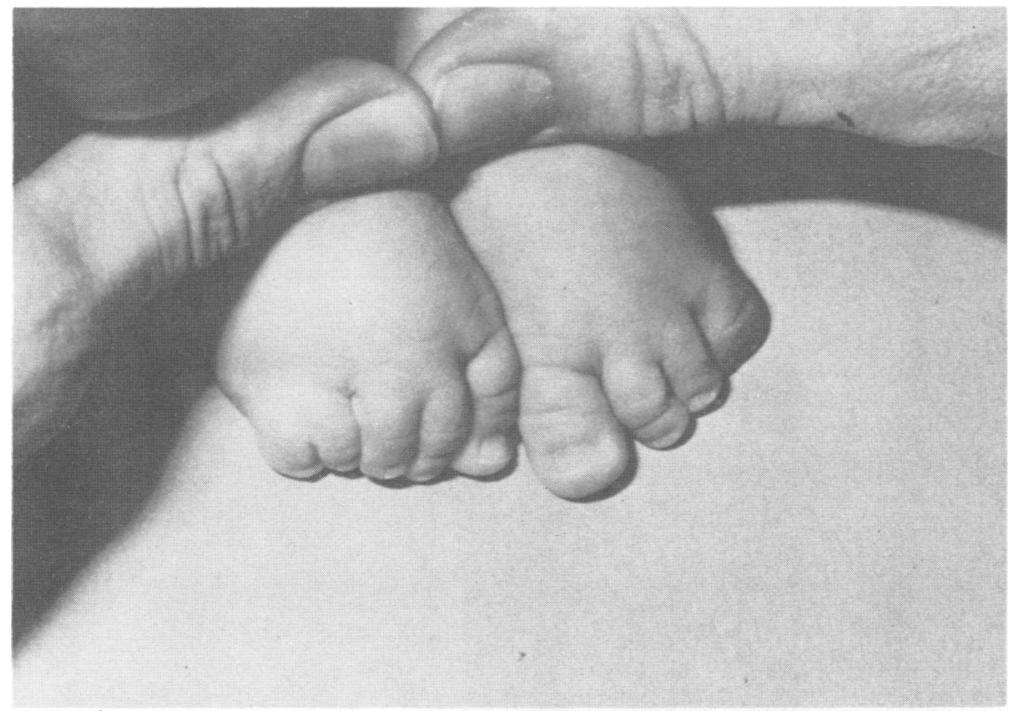

FIG 2 Feet of proband.

the right side) (fig 4a). Radiological examination indicated fusion of the second and third cervical vertebrae, an abnormally short and thin fourth metatarsal, partial duplication of the first metatarsal, and bifid terminal phalanges of both halluces (fig 4b).

Chromosomal analysis on peripheral lymphocyte cultures showed a normal $G$ banded karyotype in

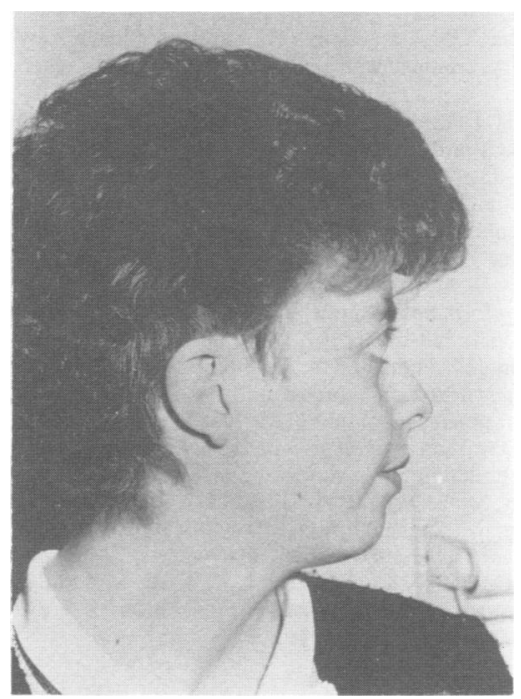

FIG 3 Face of the mother. mother and son. Further family history is negative. The mother is the youngest of seven children, her father being 39 years and her mother 38 years at the time of her birth.

\section{Discussion}

Recently Kurczynsky and Casperson ${ }^{1}$ described a mother and daughter with craniosynostosis and symmetrical syndactyly of the feet involving the fourth and fifth toes. In addition both had a short columella and small pinnae. The authors stated that the association of this particular syndactyly of the toes and the unusually shaped pinnae with craniosynostosis constitutes a new autosomal dominant acrocephalosyndactyly syndrome, and they designated it a new auralcephalosyndactyly syndrome.

The mother and son described in this paper present the same type of autosomal dominant acrocephalosyndactyly, but in addition there is a bilateral cleft lip and palate in the son, fusion of cervical vertebrae and broad halluces in the mother, and an abnormally shaped fourth metatarsal in both mother and son. These characteristics are described in the Saethre-Chotzen syndrome, another autosomal dominant acrocephalosyndactyly syndrome. ${ }^{4-6}$ The question may therefore be raised whether the family reported by Kurczynsky and Casperson ${ }^{1}$ and the present family are examples of a new auralcephalosyndactyly syndrome or represent variable expression of the Saethre-Chotzen syndrome. Furthermore, another characteristic finding in the present family is the partial polydactyly in the 


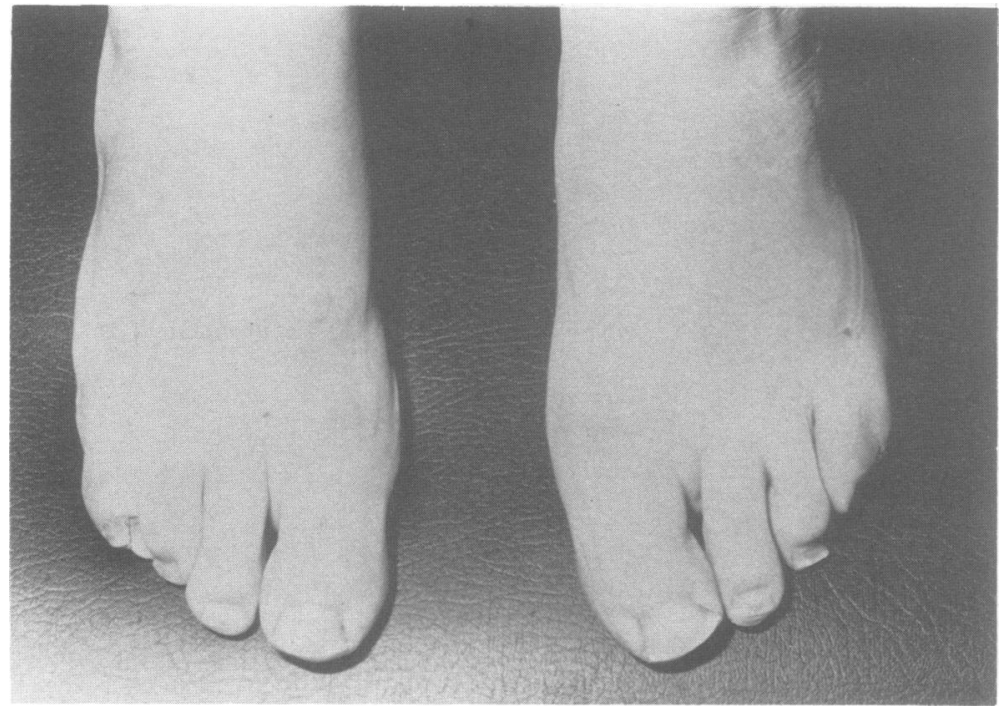

FIG 4a Feet of mother.

mother with broad first metatarsals and bifid distal phalanges of both halluces. These skeletal changes in combination with cutaneous syndactyly of the feet, abnormal auricles, and acrocephaly have been

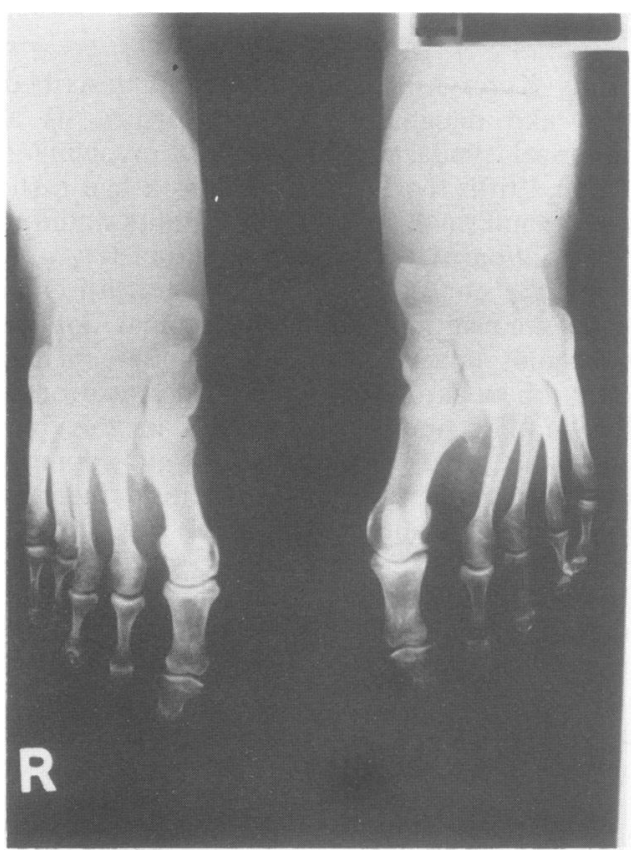

FIG 4b Radiograph of feet of mother. Note abnormal fourth metatarsal, partial duplication of first metatarsal, and bifid terminal phalanges of both halluces. described as an example of the Saethre-Chotzen syndrome ${ }^{7}$ and as the Robinow-Sorauf syndrome. ${ }^{8}$ The patients described in these two papers closely resemble the mother and son in this paper, except for the bilateral cleft lip and palate in the boy. Only the latter is reported in the Saethre-Chotzen, auralcephalosyndactyly, and Robinow-Sorauf syndromes. We do not believe that they constitute separate entities, but more likely all these families represent different expression of the same dominant gene.

\section{References}

${ }^{1}$ Kurczynski TW, Casperson SM. Auralcephalosyndactyly: a new hereditary craniosynostosis syndrome. J Med Genet 1988;25: 491-3.

2 Saethre H. Ein Beitrag zum Turmschadelproblem. (Pathogenese, Erblichkeit und Symptomatologie). Dtsch Z Nervenheilkd 1931; 117:533-55.

${ }^{3}$ Chotzen R. Eine eigenartige familiare Entwicklungsstorung (Akrocephalosyndaktylie, Dysostosis craniofacialis und Hypertelorismus.) Monatsschr Kinderheilkd 1932;55:97-122.

4 Temtamy S, McKusick V. In: Bergsma D, ed. The genetics of hand malformations. New York: Alan R Liss, Birth Defects 1978;XIV(3):328-50.

5 Friedman JM, Hanson JW, Graham CB, Smith DW. SaethreChotzen syndrome: a broad and variable pattern of skeletal malformations. J Pediatr 1977;91:929-33.

6 Smith DW. Recognizable patterns of human malformations. 3rd ed. Philadelphia: Saunders, 1982.

${ }^{7}$ Kopyść J, Stańska M, Ryżko J, Kulczyk B. The Saethre-Chotzen syndrome with partial bifidity of the distal phalanges of the great toes. Hum Genet 1980;56:195-204.

${ }^{8}$ Carter C, Till K, Frazer V, Coffey R. A family study of craniosynostosis, with probable recognition of a distinct syndrome. J Med Genet 1982;19:280-5.

Correspondence to Dr J P Fryns, Centre for Human Genetics, Herestraat 49, 3000 Leuven, Belgium. 